\title{
Fé e razão: reavaliar uma \\ relação ambígua
}

Faith and Reason: re-evaluate

an ambiguous relationship

Arquivo recebido em

5 de setembro de 2014

e aprovado em

20 de novembro de 2014

V. $4-N .8-2014$

* Doutorado em Teologia

Fundamental pela Phil.-

Theologische Hochschule

Sankt Georgen, Frankfurt,

Alemanha; Agregação em

Teologia Fundamental pela

UCP; Professor Catedrático

de Teologia Sistemática

na Faculdade de Teologia

da UCP; Desde 2011,

presidente do Centro

Regional de Braga da UCP; jmduque@sapo.pt

\section{Abstract}

\section{João Manuel Duque}

\section{Resumo}

$\mathrm{O}$ artigo pretende inserir o tópico tradicional da relação entre fé e razão no contexto da atual discussão sobre o próprio conceito de racionalidade. A partir das transformações contemporâneas, provocadas pelo impulso da razão histórica e da razão hermenêutica, propõe-se uma outra abordagem da questão, com base na consideração de uma racionalidade crente, assim como da dimensão crente de toda a racionalidade. Essa articulação fundamental, num espaço de pensamento humano comum, com dimensões diversas, não impede realizações diferenciadas da racionalidade, com as quais a fé entra em relação no exercício da sua racionalidade própria. Nesse contexto, a relação com a racionalidade estética assume um lugar privilegiado.

Palavras chave: Fé e razão, Estética, Racionalidade, Pós-modernidade.

The papers aims to enter the traditional topic of the relationship between faith and reason in the context of the current discussion on 
the concept of rationality. From the contemporary transformations caused by the impulse of historical reason and hermeneutics reason, we propose a different approach to the issue, based on consideration of a believer rationality, as the Christian dimension of all rationality. This fundamental articulation, a common human thought space with several dimensions, does not prevent differentiated achievements of rationality with which faith enters into a relationship in the conduct of its own rationality. In this context, the relationship with the aesthetic rationality takes pride of place.

Keyword: Faith and reason, Aesthetics, Rationality, Postmodernism.

A fé e a razão (fides et ratio) constituem como que as duas asas pelas quais o espírito humano se eleva para a contemplação da verdade" (FR 1). Assim começa a encíclica Fides et Ratio, que aborda explicitamente o tema que aqui nos ocupa. Nesta formulação, o assunto parece simples e pacífico. No entanto, a própria encíclica deixa antever que as coisas são mais complexas do que podem parecer à primeira vista. Logo no $n^{\circ} 4$, afirma-se: "Deve-se assinalar, porém, que, por detrás dum único termo, se escondem significados diferentes. Por isso, é necessária uma explicitação preliminar" (FR 4). Ou seja, os conceitos em causa não são unívocos e é necessário clarificar o que com eles se pretende dizer. O conceito de razão, sobretudo, foi acolhendo significados muito diversificados, estando hoje sob o fogo da discussão, mais do que nunca. Por isso, não poderemos falar da relação entre fé e razão sem uma breve consideração dessa discussão. Iniciarei a minha proposta precisamente por aí.

\section{Modelos de racionalidade}

A modernidade anunciou o poder de uma razão autónoma e unitária, que prometia uma espécie de salvação do mundo por via imanente, ou seja, pelas suas próprias forças ilimitadas. No entanto, inúmeros problemas do âmbito social ou mesmo global, levantados por esta razão forte da modernidade, desde muito cedo manifestaram a intrínseca ambiguidade da mesma. A pós-modernidade mais não faz do que colocar a claro essa profunda ambiguidade. "A razão, perante cujo tribunal (Richterstuhl) 
até agora tudo deveria responder, encontra-se, entretanto, sob acusação... Perante a dialéctica do progresso, a modernidade não pode continuar segura da sua racionalidade, nem da sua secularidade" (Höhn 1996: 13). As denúncias da razão instrumental (Horkheimer, Marcuse, Habermas), da razão identificadora (Adorno), da razão unidimensional (Marcuse), da razão funcional ou estratégica (Habermas, Apel), da razão sistémica (Luhmann / Habermas), sobretudo por parte da Escola Crítica de Frankfurt, numa aliança de leituras filosóficas e sociológico-políticas, conduziram à consciência da dialéctica, senão mesmo da aporia da razão ilustrada. Manifesta-se, assim, a consciência de que "a razão moderna não pode, ela própria, garantir as orientações de sentido, das quais na realidade vivia e das quais dependem realizações de liberdade, mediatizadas individual e socialmente" (Essen 1998: 43).

Desta dialéctica, outra coisa não se poderia esperar senão uma forte crise interna da mesma razão e, a ela ligada, uma crise das questões da verdade e do sentido. Deixa de fazer sentido falar numa razão universal, unitária, como referência última de todos os âmbitos da vida humana. $A$ meta-narrativa da única razão fundamentadora da identidade do ser humano foi despedaçada em pequenas narrativas, articuladoras de razões parciais ou fragmentárias.

Mesmo que possa ser importante defender uma razão unificadora, esta terá hoje que assumir a sua realização concreta em racionalidades parciais, sem que nenhuma dessas se afirme dominadora das outras. Trata-se daquilo a que se poderia chamar uma razão multidimensional, superadora, portanto, da moderna razão monolítica e unidimensional. Assim entendida, uma legítima crítica da razão absoluta e unidimensional, como a que foi elaborada pela pós-modernidade, não implica manter ou reacender a dicotomia entre a razão e o «outro» da razão (eventualmente o irracional, relegado para o campo do sentimento e da fé), na sua mútua concorrência. As dimensões da realidade humana são, antes, distintas dimensões da própria racionalidade. Assim acontece também com a dimensão crente, ligada eventualmente à dimensão religiosa. 
Porque não falar de uma razão crente ou da racionalidade própria da fé ou da religião, em vez de uma fé ou de uma religião por distinção - ou mesmo por oposição - à razão? É urgente, pois, repensar as categorias do relacionamento entre fé e razão, a partir de um profundo repensar das próprias categorias da racionalidade, não mais definíveis em termos modernos ou pré-modernos.

\section{Kant e as dimensões da razão}

Embora a defesa de uma razão forte e bem definida, como instrumento (tribunal) de juízo sobre o valor de verdade de tudo, seja referida frequentemente a Kant, como símbolo máximo do racionalismo moderno, o certo é que o próprio Kant pode ser perfeitamente invocado como inspirador de uma compreensão plural da racionalidade, muito além do estrito racionalismo moderno.

De facto, o tratamento do conceito mais tradicional de razão, que habitualmente ligamos de modo estreito ao conceito de ciência, é assumido por Kant apenas no contexto da crítica da razão pura (ou da pura razão teórica). Mas a racionalidade que nos permite o acesso ao real - e também, a nós próprios - pelo conhecimento, é muito mais vasta do que a permitida pela aplicabilidade do entendimento teórico, base do conhecimento científico moderno e que apenas nos permite saber o que podemos conhecer teoricamente (cientificamente). A razão prática, por exemplo, que nos permite saber o que devemos fazer e que coincide com o conhecimento ético, é outra dimensão da racionalidade, pela qual reconhecemos que a interpelação do dever nos precede, mesmo que se manifeste nas nossas capacidades racionais. Aliás, é sintomático para o nosso tema que Kant denomine este modo ético de conhecimento como fé filosófica. De facto, o conhecimento do que devemos fazer acontece como exigência de uma resposta da liberdade humana a uma interpelação que não é produto dela mesma - e é isso precisamente que define o conhecimento crente (Cf. Duque 2004). 
Mas Kant não se ficou pela análise das possibilidades da razão prática. A crítica do juízo pode ser considerada um estudo sobre a razão imaginativa, que coloca no seu centro a questão do desejo e da esperança, ligados à dimensão estética da racionalidade. Trata, precisamente, sobre aquilo que nos é permitido ou dado a esperar. $E$ isso é, precisamente, o que anima o desejo humano, servindo de base à sua capacidade de imaginar um futuro desejado. Essa dimensão do sentimento é, também ela, uma dimensão da racionalidade humana - em rigor, a dimensão mais profunda, pois é pela esperança que, segundo Kant, podemos imaginar - e de certo modo conhecer - a esperada coincidência entre o que deve ser feito e a bem-aventurança da felicidade daí resultante. Trata-se pois, de uma dimensão sentimental ou afectiva da razão, como elemento mais profundo da definição do humano.

Ora, esta dimensão afetiva da racionalidade, com o seu impacto na razão crente, tem recuperado o seu lugar na reflexão filosófica e teológica contemporânea. O teólogo e filósofo de Milão, Pierangelo Sequeri, num livro recente, intitulado O amor da razão (Cf. Sequeri 2012), estabelece um relação estreita entre o afecto e a racionalidade, na medida em que o próprio amor à razão constitui, ele próprio, já uma dimensão da racionalidade. Ao mesmo tempo, o amor possui, em si mesmo, uma razão própria. O que permite falar não apenas no amor da razão mas na razão do amor. E assim se supera a redução da racionalidade à necessidade lógica, assente no princípio da razão suficiente, abrindo o espaço de um excesso de sentido, como dádiva gratuita, que acolhe uma racionalidade afectiva própria. O conhecimento do real assume, assim, as características de um sentimento que precede toda a lógica. A razão não é, pois, uma faculdade monolítica, segundo o modelo lógico-empírico de conhecimento da realidade.

Esta questão da pluralidade da razão, articulada em diferentes racionalidades, passa a ser o tópico fundamental da denominada cultura pósmoderna, que pode ser considerada a cultural atualmente dominante. 


\section{Razão transversal}

Wolfgang Welsch, principal representante alemão da filosofia pósmoderna, propõe uma concepção de razão mais moderada do que a do conhecido autor de a condição pós-moderna, Jean-François Lyotard, que desemboca na afirmação absoluta de heterogeneidades irredutíveis, a ser nomeadas de forma justa, como diferendos não solúveis no consenso global; o conhecido filósofo americano Richard Rorty tirava disso uma consequência anti-epistemológica, colocando todo o saber no contexto imanente a sistemas de descrição, insuperavelmente contingentes e, por isso, sem pretensões de verdade; contudo, coloca-se o problema da possibilidade mesma de nomear essas heterogeneidades e esses contextos, sem uma razão que possibilite essa mesma nomeação e que permita a comunicação entre elas. Frente a esta aporia, Welsch propõe um tipo de razão (muito semelhante à da filosofia edificante de Rorty, mas também à dialéctica de Platão e à filosofia da imaginação, na terceira crítica kantiana ${ }^{1}$ ) que possibilite preencher essa lacuna, sem pretender assumir o papel da forte razão global moderna. A semelhante tipo de razão, chama-lhe «razão transversal», atribuindo-lhe o papel de ponte horizontal entre os mundos e os contextos irredutivelmente plurais. Desse modo, pretende evitar-se o perigo do total irracionalismo da pós-modernidade que encontra, na razão transversal, a sua «razão» específica: uma forma de racionalidade aberta à pluralidade dos saberes e das articulações, mas que não abdica da pretensão de racionalidade. "Como razão é para nós, hoje, válida - orientada para a pluralidade uma faculdade de ligação e de passagem entre as formas de racionalidade" (Welsch 1996: 195). Como tal, a proposta de Welsch encontrase entre a modernidade absoluta (para quem é de admirar que sejam problemáticos os intercâmbios entre as formas de racionalidade, pois todas se encontram emergidas na razão universal) e a pós-modernidade radical (para quem tais intercâmbios são absolutamente impossíveis). "A 
consciência filosófica conhece, por entre elas - na estreita, mas múltipla zona das transições - o caminho real da razão" (Welsch 1996: 205). De facto, a insolubilidade dos dissensos, a irredutibilidade do heterogéneo só se tornam experimentáveis e definíveis no seio dessa mesma razão - que de modo algum significa a imposição de um tipo de racionalidade a outros.

\section{A teologia e a razão crente}

Recentemente e em oposição a um caminho de aproximação da ciência teológica - e da racionalidade que a determina - à epistemologia do racionalismo crítico, que se mantinha muito prisioneiro de uma visão monolítica da racionalidade, uma série de projetos teológicos tem-se concentrado mais intensamente na «lógica» interna da teologia - enquanto «lógica» da própria fé - encontrando aí o fundamento da sua racionalidade, e não propriamente no recurso a modelos exteriores ${ }^{2}$. Outros, mantendo embora a referência a uma racionalidade «externa», porque com pretensão universal, não aceitam que a racionalidade teológica se possa reduzir a uma racionalidade hipotética, sujeita ao princípio da falsificabilidade. Assim, as tentativas recentes de epistemologia da fé poderiam situar-se entre uma perspectiva mais exterior - cientificidade procurada no encontro com a noção geral de ciência ou noção universal de racionalidade - e uma perspectiva mais interior - cientificidade encontrada na especificidade de uma lógica racional interna ao universo crente. O teólogo alemão Ingolf Dalferth, por seu turno, parece assumir uma posição intermédia, na medida em que se orienta para uma perspectiva sistémica, por isso interna, mas defende uma relação específica com outros contextos, exteriores ao da comunidade crente, apresentando uma compreensão metodológica da teologia como «teologia combinatória» (Cf. Dalferth 1991).

2. É essa, pelo menos em parte, a perspectiva de correntes anglo-saxónicas hoje muito determinantes, como é o caso da teologia pós-liberal de G. Lindbeck e da Ortodoxia Radical de J. Milbank. 
De qualquer modo, a questão da cientificidade da teologia parece exigir que a questão da coerência sistemática, ou a ausência de contradição - numa compreensão da verdade como pura coerência sistémica - deva ir mais longe do que a orgânica interna da comunidade crente. Em última instância, a dimensão da racionalidade implica certa orientação universal das pretensões teológicas. Como tal, a lógica interna da teologia - que possui uma legitimidade própria, pois qualquer ciência possui uma coerência que só lhe pode ser interna - não poderá esquivar-se às exigências de uma dimensão universal das suas afirmações e perspectivas. A este nível, situar-se-iam aquelas posições que defendem, explicitamente, que a cientificidade da teologia não pode desligarse da sua dimensão "metafísica» ou transcendental (Cf. Splett 1996; Schaeffler 1980, 1982).

$\mathrm{Na}$ base da questão da cientificidade - e também das discussões sobre a fundamentação interna ou externa da cientificidade teológica e da racionalidade crente que lhe serve de base - encontra-se, sem dúvida, a questão geral do conceito de racionalidade, tal como a colocamos acima. Certa univocidade do conceito de ciência assentou, pelo menos durante algum tempo, em certa univocidade do conceito de razão. Ainda hoje, quando se fala na relação entre fé e razão, pressupõe-se implicitamente essa univocidade. Mas o conceito de razão é tão pouco unívoco como o de ciência. Nesse sentido, a dimensão racional da teologia, enquanto intellectus fidei, pressupõe um conceito plural de racionalidade, ao qual nos referimos acima. Para além da distinção entre racionalidade interna - que se baseia em modelos sistémicos, segundo a perspectiva wittgensteiniana dos jogos de linguagem - e racionalidade externa - assente numa orientação universalizante, seja através de uma linguagem comum, seja através de permuta de perspectivas - muitas outras abordagens racionais do real se poderiam apresentar. Nesse sentido, um elemento fundamental do intellectus fidei não seria, eventualmente, a confirmação dos conteúdos da fé, através do recurso a uma racionalidade externa, pretensamente universal e abstratamente idêntica (ou unívoca) 
em todos os seus usos, mas antes a avaliação da própria dimensão racional do crer. Estaremos, assim, perante uma racionalidade crente ou, pelo menos, perante a dimensão crente de toda a racionalidade. A racionalidade crente estaria determinada por todos os elementos que definem a fé como atitude de escuta de uma interpelação exterior, à qual o crente adere em liberdade, sem uma necessidade específica imposta pela lógica ou pela ciência. Essa atitude é fundamental para a compreensão da própria existência, mesmo para a base de todo o saber e de todo o fazer. A dimensão mais explicitamente racional do intellectus fidei será assim intrínseca ao próprio ato de crer e não um acrescento a posteriori, para sua eventual validação puramente racional.

Assumido o facto de que o processo crente possua uma racionalidade própria, esta não pode, contudo, reduzir-se ao seu dinamismo interno, como se fosse incomensurável. De facto, a tradição do intellectus fidei sempre supôs, também, a capacidade de diálogo da racionalidade crente com outros modos de racionalidade - sendo esta capacidade de diálogo, por seu turno, também uma característica da própria racionalidade crente. Assim sendo, a ciência teológica - enquanto atividade específica de intellectus fidei - implica uma racionalidade em permanente diálogo com outras ciências ou com outros modos de racionalidade, que evita a redução à estrita racionalidade crente, mesmo que esta constitua a base e o ponto de partida de qualquer diálogo deste tipo.

Mesmo que seja, atualmente, difícil a referência a uma racionalidade universal abstracta - como esquema ou estrutura de pensamento que pudesse existir «em si» (no sentido das categorias kantianas da razão pura, por exemplo) independentemente da sua aplicação histórica num modo concreto de racionalidade - não deixa de ser importante que a teologia não esqueça, no seu caminho ou método, a apologia da sua verdade, enquanto apresentação pública da sua própria racionalidade. Ora, essa apresentação pública acontecerá, atualmente, sobretudo no debate dialógico das diferentes racionalidades, superando as afirmações absolutistas de algumas delas - como aconteceu com o positivismo 
lógico-empírico e como parece acontecer hoje com certo cientificismo neo-ateísta. A função desse debate é, ao mesmo tempo, a de manter viva a exigência de autocrítica da própria racionalidade, por confronto com outras perspectivas, e também a de contribuir para uma crítica das pretensões desmedidas de outras racionalidades.

Nesta relação com outras áreas do saber - sobretudo das denominadas ciências humanas, mas não exclusivamente - é que deverá desenvolver-se uma parte da dimensão crítica do método teológico. De facto, a consciência da inserção histórica e hermenêutica desse método, que implica a aceitação da pertença a uma tradição e a um contexto de interpretação, não pode invalidar a necessidade de recurso a metodologias de controlo crítico, que permitam evitar ilusões ou mesmo distorções sistemáticas. A suspeita da possibilidade dessas distorções deve manter-se presente, ao longo do caminho teológico, para evitar que o pretenso discurso crente seja mera repetição ideológica de elementos pré-estabelecidos, potencialmente manipuladores. É claro que este trabalho crítico, com recurso a metodologias próprias de outras ciências - com saliência para a sociologia, a história, mesmo a psiquiatria e a semiótica - não significa a aceitação dessas metodologias como critério extrínseco absoluto (o que significaria simples repetição do recurso iluminista ao pretenso tribunal da razão, como terreno neutro, capaz de julgar objectivamente as afirmações teológicas) ${ }^{3}$. Mas a exigência de participação no debate público, e a própria exigência intrínseca de verdade, impedem a teologia de se alhear desse trabalho crítico, que ajudará a evitar, de facto, muitas conclusões claramente perversoras da sua própria verdade.

Encontramo-nos, assim, no seio de um dos elementos fundamentais do intellectus fidei: a dimensão (auto)crítica da fé e da correspondente teologia. Acusada frequentemente de dogmatista, a teologia é considera-

3. Considero perspicaz e adequada a crítica que J. Milbank (cf. Milbank 1990), faz a este tipo de subjugação da teologia a certas ciências humanas, sobretudo à sociologia, como se estas fossem as "ciências primeiras». 
da, precisamente, como isenta de atividade crítica. Ora tratar-se-á, precisamente, do inverso. O próprio núcleo do «objecto» da teologia - seja, genericamente considerado, o próprio Deus, enquanto prima Veritas, seja, especificamente, o conteúdo da fé, enquanto único modo de relação com o primeiro - implica uma permanente crítica das afirmações teológicas, que serão sempre, do ponto de vista fundamental, desadequadas ao seu objecto. Assim sendo, o método teológico é o caminho da permanente auto-crítica de todas as afirmações. As suas possibilidades positivas só são aceitáveis, tendo em conta esta dimensão negativa do seu trabalho.

Não se trata, contudo, de racionalismo crítico propriamente dito, pois a crítica não se realiza por referência a critérios construídos por uma pretensa racionalidade humana absoluta. Mesmo que essa racionalidade assentasse no princípio da falsificação permanente, a identificação desse princípio com a verdade absoluta do método seria, por si só, uma afirmação desmedida da própria razão. A racionalidade teológica, precisamente por ser teológica, liberta o logos humano dessa pretensão absolutizante, a partir de si mesmo. A sua relação com a verdade, que potencia o logos humano para afirmações com validade, é sempre a relação com uma verdade dada e não construída a partir do interior da racionalidade. Trata-se, pois, de uma racionalidade de resposta, de correspondência. Nesse sentido, a verdade da fé e da teologia não lhe é garantida por um caminho auto-construído por uma racionalidade própria, através do percurso metódico do teólogo. A verdade da teologia é uma oferta que o método ajuda a acolher, na medida em que vai eliminando tudo aquilo que impede esse acolhimento. Atingimos, assim, uma compreensão fenomenológica do método e da correspondente racionalidade. A verdade da fé e da teologia, enquanto verdade dada fenomenologicamente, não é por isso menos verdade nem é menos a manifestação da verdade do ser e do sentido de tudo aquilo que é.

É precisamente nesta dimensão da doação fenomenológica da verdade interpeladora da teologia e do seu método (científico) que se pode 
compreender o lugar da estética - nomeadamente da arte - para a teologia e o significado de uma estética teológica. Comecemos por esta última. Se o trabalho do intellectus fidei coloca a fé na sua relação crítica com as racionalidades diversas, o seu ponto de partida é sempre o auditus fidei inicial, ou seja, a atenção e o colhimento ao que é dado, fenomenológica e historicamente, a acreditar. Esse processo originário é um processo de percepção sensível, um processo estético de acolhimento de algo dado a sentir: trata-se do affectus fidei que origina todo o processo da fé. A racionalidade crente - teologicamente considerada, mas não só - é inevitavelmente marcada pelo momento estético (correspondente à aisthesis que determina o nosso ser no mundo) da sua constituição originária, como fonte de qualquer processo de intellectus fidei e mesmo de actio fidei. Nesse sentido, a racionalidade crente é originariamente estética - no caso concreto da fé cristã, como estética concentrada na doação fenomenológica da pessoa de Jesus Cristo. Uma estética teológica é aquela que explora precisamente a dimensão estética do próprio ato de fé e da teologia correspondente.

Ao mesmo tempo, esse movimento estético originário está já habitado por uma dimensão crítica. Primeiro, porque a permanente diferença entre o que nos é dado a acreditar (fides quae) e o ato pelo qual acreditamos (fides qua) implica a permanente crítica do próprio ato e das formulação que com ele se relacionam. Depois, porque do acontecimento estético que origina a fé é colocado em permanente relação com outras manifestações da experiência estética do real, evitando - à semelhança o que acontece com o intellectus fidei - o encerramento da estética teológica num universo sistemicamente fechado. É nesse sentido que a relação com outras fontes de experiência estética - como a arte, em todas as suas formas, e a literatura em particular - constitui um permanente desafio crítico e inspirador para uma estética teológica que, partindo embora da doação originária de uma figura histórica (Jesus Cristo), elabora a sua hermenêutica crítica em permanente diálogo com a experiência estética das doações históricas que acompanham a nossa 
existência, na sua infinita variedade, e que arte consegue mediar de forma muito própria.

\section{Bibliografia}

Höhn, H.-J. (1996). Krise der Immanenz. Religion an den Grenzen der Moderne. Frankfurt a. M: Fischer Verlag.

Essen, G. (1998). "Und die Zeit ist unsere Zeit, immer noch". Neuzeit als Thema katholischer Fundamentaltheologie. In: K. Müller, K. [ed.]. Fundamentaltheologie. Regensburg: Puster Verlag. 23-44.

Duque, J. M. (2004). Homo credens. Para uma teologia da fé. Lisboa: UCEditora.

Duque, J. M. (2011). "Teologia e arte: fundamentos epistemológicos". In: Mariani, Ceci Baptista / Vilhena, Maria Ângela (org.s), Teologia e arte: expressões de transcendência, caminhos de renovação, S. Paulo: Paulinas, 15-27.

Sequeri, P. (2012). L'amore dela ragione. Bologna: EDB.

Welsch, W. (1996). Vernunft. Die zeitgenössische Vernunftkritik und das Konzept der transversalen Vernunft. Frankfurt a. M.: Suhrkamp.

Dalferth, I. U. (1991). Kombinatorische Theologie. Probleme theologischer Rationalität. Freiburg i. Br.: Herder.

Splett, J. (1996). Denken vor Gott. Frankfurt a. M.: Knecht.

Schaeffler, R. (1980). Glaubensreflexion und Wissenschaftslehre, Freiburg i. Br.: Herder.

Schaeffler, R. (1982). Fähigkeit zur Erfahrung. Zur transzendentalen Hermeneutik des Sprechens von Gott. Freiburg. i. Br.: Herder.

Milbank, J. (1990). Theology and Social Theory. Oxford: Blackwell. 